\title{
Tosinas
}

\section{La represión cultural en la última dictadura cívico-militar: identidad(es) en peligro}

Cielo Morbelli

Licenciada en Trabajo Social

(Universidad Nacional de Rosario)

Correo: cielo.morbelli@gmail.com 
Resumen

En el trabajo se analiza la represión cultural llevada adelante por la última dictadura cívico-militar, particularmente sobre las personas que hoy podríamos enmarcar en el colectivo LGTBI. El régimen dictatorial que implantó en el país el "Proceso de Reorganización Nacional" debe ser entendido como una práctica social genocida, en su aspecto reorganizador. En este sentido, mediante el intento (des) medido de reconfigurar las relaciones sociales vigentes, se avanzó violenta y decididamente en la búsqueda de aniquilar todas aquellas relaciones que encarnaban valores que “debían" ser desterrados. Fue así como, mediante la construcción de una otredad negativa, se creó en el imaginario colectivo la figura del "subversivx delincuente", bajo la cual englobaron a toda persona que levantase las banderas de la igualdad, autonomía y solidaridad. En este marco, bajo el lema de la "Civilización Occidental Cristiana", se avanzó también sobre quienes, alejándose de la norma, pretendían escoger libremente su orientación sexual y/o su identidad sexual. Hasta el día de la fecha no se han reconocido oficialmente los padecimientos a los que fueron expuestos unos 400 homosexuales, lesbianas y mujeres trans. El presente artículo busca ser un aporte en este sentido, y una reafirmación de aquellas prácticas que encarnaron nuestrxs compañerxs desaparecidxs.

Palabras claves

Práctica social genocida Comunidad lgtbi - Memoria

\section{Abstract}

This article analyzes the cultural repression carried out by the last military dictatorship, particularly on those who nowadays could be considered as part of the LGBTQIA+ community. The "National Reorganization Process" should be understood as a genocidal social practice, in its reorganizational aspect. In an excessive attempt to reconfigure the existing social relations, a violent and resolute process was carried out with the aim of annihilating all those relationships considered to embody values that "should" be banished. It was in this way, through the construction of a negative otherness, that the figure of the "subversive delinquent" was created in the public imagination, and included under this figure were all those who raised the flags of equality, autonomy and solidarity. In this context, under the slogan of "Western Christian Civilization", those who, away from the "norm", wanted to freely choose their sexual orientation or sexual identity were also affected. So far, there has not been an official recognition of the sufferings to which approximately 400 gay, lesbian and trans women were exposed. This article seeks to be a contribution in this regard, and a reaffirmation of those practices that embodied our missing colleagues.

Keywords

Social genocide practice - Lgbtqia+ community - Memory 


\section{Introducción $^{1}$}

La dictadura cívico militar implantada en la Argentina durante los años 1976-1983, sumergió al país en un proceso que puede ser categorizado como una práctica social genocida, en su aspecto "reorganizador", según la propuesta teórica de Daniel Feierstein. El autodenominado "Proceso de Reorganización Nacional" implantó el terror como medio y fin para conseguir el reordenamiento de la sociedad según valores por ellxs² mismxs definidos, en la búsqueda de la "civilización occidental y cristiana", como solían proclamar orgullosamente, tanto los altos mandos militares como lxs perpetradorxs en las salas de tortura.

El plan que llevaron a cabo, con complicidad de múltiples países latinoamericanos y de potencias como EE. UU. ${ }^{3}$, puede ser desandado en numerosos aspectos: políticas económicas que favorecieron solamente al sector del capital, violaciones sistemáticas a los derechos humanos, abusos de poder y autoridad, complicidades cívicomilitares para instalar el miedo, centros clandestinos de tortura y exterminio, campañas del terror con una fuerte impronta dogmática, robo de bebxs, por mencionar algunos.

Se centrará el análisis específicamente en la represión cultural y, en particular, en los derechos vulnerados de lxs sujetxs que hoy podrían identificarse o sentirse parte del colectivo de Lesbianas, Gays, Transexuales, Bisexuales e Intersex ${ }^{4}$. Se estima que, en este período, unas 400 personas fueron perseguidas, detenidas, torturas, desaparecidas, incluso muertas, por su orientación y/o identidad sexual. Se

1 El presente trabajo surge en el marco de la propuesta formulada por la Cátedra "Memoria, Identidad y Política: discursos y construcciones de sentido en torno a la última dictadura cívicomilitar”, cursada en 2016 como estudiante de Trabajo Social, en la Universidad Nacional de Rosario.

2 Se utilizará la letra "x" como opción ética-política que busca referirse a un universo amplio de expresiones de género, que vaya más allá del dualismo "hombres” y "mujeres", y que contemple también a transexuales, transgéneros, intersex u otras que vayan a existir.

3 Esto queda evidenciado en la participación de la Argentina en el Plan Cóndor. Para más información sobre este último, se recomienda leer "El Plan Cóndor: origen, desarrollo y consecuencias (1973/1983), de Cecilio Salguero, disponible online en: http://www.papelesdesociedad.info/IMG/pdf/ el-plan-condor.pdf

4 Cabe aclarar que en la década del 70 el movimiento LGTBI aún no se encontraba constituido como tal, sin embargo, sí existían ciertos niveles de organización, que serán abordados más adelante. 
puede afirmar que hoy permanece invisibilizada ${ }^{5}$ la experiencia particular padecida por este colectivo. Es este el motivo que moviliza y anima el presente trabajo, acompañado por el deseo personal y recorrido militante que convocaron a realizarlo.

\section{Para entender(nos)}

Se realizarán las pertinentes aproximaciones teóricas a las categorías "sexo", "género", "identidad sexual" y "orientación sexual". Luego, se planteará una distinción entre "población", "comunidad" y "colectivo", para entender a qué se hará referencia cuando se mencionen dichos términos.

Sexo, género, identidad sexual, orientación sexual

El "sexo" puede ser definido como aquellas características físicas, cromosómicas y fisiológicas de los seres humanos. A los fines del presente trabajo, se expondrá esta como definición, asumiendo las simplificaciones realizadas.

El concepto "género" intenta describir un fenómeno de carácter cultural (lo que se concibe como "masculino" y "femenino" no es natural y universal, sino que es construido y difiere según las culturas, las razas, las religiones), histórico (lo que cada cultura entiende cómo "masculino" y "femenino" varía de acuerdo a los diferentes momentos históricos) y relacional (lo que se entiende por masculino se define en relación a lo que se entiende por femenino, y viceversa, en un horizonte de significaciones mutuas).

El género, entonces, es un concepto formulado para contestar la naturalización de la diferencia sexual en diversos ámbitos de lucha ${ }^{7}$.

5 Tampoco es casual que en el Nunca Más —el primer informe oficial— no se nombra ni siquiera a una sola persona detenida o desaparecida a causa de orientación sexual o su identidad sexual.

6 No se prestará especial atención a la discusión entre "sexo" y "sexuación”, sumamente interesante, pero detenerse en ello no será posible por motivos de extensión.

7 El concepto de género no surge desde los estudios feministas, ni mucho menos con el objetivo de ampliar las libertades de lxs sujetxs, sino que fue desarrollado por lxs médicxs comprometidxs con los tratamientos de reasignación de sexo a personas intersexuales: su compromiso no era con esas personas, sino con la adecuación de los cuerpos de las mismas a la bi-categorización sexual heteronormativa y dicotómica. 
La teoría y práctica formuladas por los feminismos, con relación al mismo, tratan de explicar los sistemas históricos de diferencia sexual, con el fin de transformarlos. Como parte de esta naturalización, varones y mujeres aparecen constituidxs y situadxs socialmente en relaciones de jerarquía; las cuales aparecen como "a-históricas" e "inamovibles": el feminismo asume como tarea correr este manto.

Cabe aclarar que la utilización acrítica de este arsenal teórico - aquí sumamente reducido a una líneas - tiene fuerte impacto en las concepciones que subyacen a las políticas estatales y a las iniciativas que promueven la mayor parte de las organizaciones sociales de mujeres o incluso feministas.

En tercer lugar, según Fabbri (2013), se entiende por "identidad de género" el sentimiento de pertenencia al sexo femenino o masculino de un individuo. La identidad de cada quien se construye en base a la subjetividad, las experiencias históricas y los modelos de género existentes en la sociedad. Por lo general, dicha construcción se basa en valores que corresponden a modelos de comportamiento aceptados socialmente como válidos y naturales. En la actualidad, existe un modelo predominante de identidades de género, que se erige como norma, establece espacios para mujeres y varones, señala lo permitido y prohibido, establece visiones estereotipadas de los géneros y una valoración diferencial de lo definido como femenino y masculino, en desmedro del primero. En una sociedad estructurada de manera binaria, cuya principal forma de organización es la heterosexualidad obligatoria basada en las ideas de complementariedad y mutua exclusión, la mayor parte de lxs sujetxs trans se autoperciben en las categorías hegemónicas, hacia las cuales tienden a desplazarse en la transformación de sus cuerpos y atributos culturales.

Por último, y siguiendo la propuesta del mismo autor, se entiende a la "orientación sexual" como el deseo de mantener relaciones sexo-afectivas con personas de determinados géneros. En general se presenta como una elección estática: la mayoría se identifica como "heterosexual". Otrxs se definen "homosexuales", en el caso de sentirse atraídos por personas del mismo género. También existe la "bisexualidad", generalmente invisibilizada incluso hacia dentro del 
movimiento LGTBI, que es la definición que adoptan las personas que sostienen vínculos sexo-afectivos, tanto con mujeres como con varones. Recientemente acuñado es el término "pansexualidad", que define a aquellas personas que expresan sentirse atraídas sexual o emocionalmente por cualquier persona más allá de su sexo o género. Sin embargo, en tanto el deseo es fluctuante, en los diversos procesos de constitución subjetiva y desplazamientos vitales, una misma persona puede definirse (tanto su identidad como su orientación sexual) de distintas maneras a lo largo del tiempo ${ }^{8}$.

\section{Población, comunidad, colectivo ${ }^{9}$}

El denominador común entre los tres términos es que hacen referencia a discursos que están nombrando al "otrx" reveladx como diferencia. Sin embargo, es oportuno exponerlos por separado para plasmar las diferencias en su utilización.

Por un lado, cuando se hace mención a "población homosexual" o "población diversa", se puede identificar en este concepto la necesidad de poner evidencia y denunciar el discurso médico higienista de los años treinta ${ }^{10}$ que buscó medicalizar el deseo no heteronormado y ubicarlo como un abyecto. Por otro lado, cuando se refiere a los "colectivos de diversidad sexual”, se hace hincapié en la dimensión política organizativa y a los procesos de lucha y reivindicaciones por los derechos de la ciudadanía plena. Por último, el término "comunidad" implica un entramado de prácticas, discursos, instituciones, actores que van delineando un campo denominado disidencia afectiva o de diversidad sexual, siempre en términos de disputa con la sexualidad heteronormativa y hegemónica.

8 Esto constituye una simplificación, ya que suelen existir barreras culturales que limitan la elección.

9 Esta distinción es retomada de un trabajo final de la asignatura Práctica Profesional II (Facultad de CCPP y RRII, UNR) realizado en el año 2014 por Elizalde, Agustina; Morbelli, María Cielo y Peralta, Marcos.

10 A grandes rasgos, el higienismo consideraba a la homosexualidad como una enfermedad, y se pretendía "curarla" con tratamiento psicológico, por medio de la generación de culpa y la represión estatal. 


\section{El genocidio como práctica social}

En primer lugar, cabe aclarar que en este trabajo se opta por conceptualizar al autodenominado "Proceso de Reorganización Nacional" como un genocidio de tipo "reorganizador". Esta propuesta, si bien es asumida como propia, se encuentra inspirada fundamentalmente en el libro El genocidio como práctica social, de Daniel Feierstein. Según la tipología propuesta, el caso argentino fue un genocidio de tipo "reorganizador", en tanto genocidio político dirigido a toda la sociedad, que buscó refundar un Estado preexistente, gracias a la transformación de las relaciones sociales hegemónicas al interior del mismo. Para ello, utilizó el terror, el aniquilamiento y la modalidad concentracionaria como tecnología específica para llevarlo a cabo.

Feierstein se distancia del concepto de "guerra" y la consecuente "teoría de los dos demonios" —noción hegemónica de los años ochenta para explicar los hechos sucedidos la década anterior- a través de la cual se pensaba al conjunto social como víctima de dos tipos de agresión: "durante la década del setenta, la Argentina fue convulsionada por un terror que provenía tanto desde la extrema derecha como de la extrema izquierda", sentenció Sabato en el prólogo al Informe Nunca Más, publicado en septiembre de 1984 por la Comisión Nacional sobre la Desaparición de Personas (CONADEP). Sin pretender abarcar la totalidad de la discusión con respecto a esta teoría, se transcribe un fragmento Daniel Feierstein, por su gran claridad para plasmar las concepciones que subyacían al mencionado Informe: “...instala la idea de «inocencia» de las víctimas como oposición a la posibilidad de culpabilidad (que queda en sujeto tácito) de los "cuadros combatientes de la guerrilla», a la vez que sostiene el prejuicio de que éstos morían en combate cuando la mayoría, más allá de su pertenencia política o de su relación con la lucha armada, habían sido víctimas de los campos de concentración, tan víctimas - y es ello lo que no se quiere asumir en el Informe- como quienes no pertenecían a dichos conglomerados políticos" (Feierstein, 2007:270). 
Esta teoría obtuvo una gran adhesión social, en tanto entiende a la misma sociedad como un ente abstracto, una víctima colectiva de aquellos demonios, por lo cual no le cabe a ésta ningún tipo de problematización ética y moral sobre su rol en este período. Vale aclarar que en este último año ciertos sectores han buscado volver a instalar esta teoría.

Varixs autorxs han concebido al período estudiado por medio de la noción de "Estado Terrorista", entre ellxs Eduardo Luis Duhalde y Guillermo O'Donell (con sus matices). Duhalde (1999) entiende que el objetivo central del Estado dictatorial fue la desarticulación de la sociedad. El autor rechaza el concepto de guerra, en tanto ésta implica un carácter simétrico que no fue tal. A su vez, afirma que lxs victimarixs hicieron uso de su capacidad de hegemonizar la violencia, actuando en la superficie ${ }^{11}$ con un tinte de legalidad y garantía de derechos, mientras que por debajo coexistían numerosos delitos, violaciones, torturas y numerosos hechos planificados que atentaron contra los derechos de lxs ciudadanxs. Por sobre todo, tanto a la luz del día como en la oscuridad de los centros clandestinos: el terror, como método prioritario para hacerse de sus propósitos.

Feierstein (2007), se propone "comprender al aniquilamiento de colectivos humanos como un modo específico de destrucción y reorganización de relaciones sociales", ya no sólo visto como una "posibilidad" de la modernidad, sino entendiéndolo como una "tecnología de poder ${ }^{12}$ peculiar, con causas, efectos y consecuencias específicos".

Interpretar el aniquilamiento de ciertos colectivos sociales como una práctica social (genocida), tiene grandes potencialidades para el análisis, en tanto ayuda a entender que la lógica concentracionaria no fue sólo (como si esto fuese poco) el acto de secuestrar, torturar y desaparecer físicamente a " $\mathrm{x}$ " cantidad de personas: el genocidio se

11 La noción de "superficie" y "bajo tierra" fue tomada de una clase a cargo de Sabrina Gullino y Matías Gómez, docentes de la materia electiva que enmarca el presente trabajo.

12 Por tecnología de poder se entiende "una forma peculiar de estructurar — sea a través de la creación, destrucción o reorganización - relaciones sociales en una sociedad determinada [...] la identidad de sus semejantes, y la alteridad de sus «otros»" (Feierstein, 2007:26). 
dirigió a todo el conjunto social, no solo a aquellxs internadxs en los campos.

En esta lógica, se puede afirmar que Argentina — toda ella- fue víctima de una práctica social genocida de tipo "reorganizador" que tuvo la particularidad de exhibir una "gran capacidad para destruir y reorganizar relaciones sociales" (Feierstein, 2007:13) de acuerdo a valores impuestos por lxs perpetradorxs. Sobre este último punto se volverá más adelante, dada la importancia y consecuencias inimaginables que trae aparejada tal amenaza y violación sistemática a los valores de una sociedad. Ser libres para (decidir a quién) amar, ser libres para elegir organizarse y luchar. Si estas libertades (entre otras) son arrebatadas, la constitución misma de cada persona del territorio queda trunca, al coartársele las posibilidades de desenvolvimiento y las maneras de relacionarse para con lxs otrxs.

\title{
"Civilización occidental y cristiana": la represión cultural y el intento (des) medido de aniquilar identidades
}

\author{
"Primero mataremos a todos los subversivos, \\ luego mataremos a sus colaboradores, \\ después a sus simpatizantes; \\ luego a aquellos que permanecen indiferentes \\ y, finalmente, mataremos a los tímidos". \\ Mayo 1977, Gral. Saint Jean
}

Daniel Feierstein (2007) desarrolla una periodización, inspirado y estudiando con especial fervor dos procesos históricos: el genocidio realizado por el nazismo entre 1933 y 1945, y la última dictadura cívico-militar argentina. Dicha periodización consta de seis momentos que se articulan teniendo como eje principal al conjunto social en el cual el genocidio se lleva adelante. Ambos procesos, obviamente con sus particularidades, no buscaron sólo aniquilar una parte de la población, sino que su objetivo último fue la búsqueda de la reformu- 
lación las relaciones sociales. Las personas llevadas a los campos de concentración no eran las destinatarias únicas del accionar: constituían, más bien, la encarnación de ciertos modos de relacionamiento y de valores vigentes contrarios a los que querían imponerse, por eso fueron eliminadas, difuminando el terror.

Los procesos estudiados por dicho autor inician con un momento muy importante: la determinación de la otredad negativa, mediante la cual se persigue "la construcción negativizante de la identidad del sujeto social delineado como «otro» (aquel que es capaz, aún de apropiarse de su práctica y su experiencia, haciendo primar la autonomía en sus decisiones)" (Feierstein; 2007:215). El recorrido termina en la "realización simbólica": instancia vinculada a las formas de narrar y representar dichas experiencias, con el objetivo de perpetuar la lógica y los valores genocidas ${ }^{13}$. Sobre esto se volverá más adelante, relacionándolo con el caso particular de la persecución y exterminio de personas con sexualidades disruptivas.

La dictadura en la Argentina llevó adelante una fuerte represión cultural que buscó eliminar del escenario a todxs aquellxs que albergaran valores que fuesen opuestos a lxs que ella pretendía instalar. A continuación, se profundiza el análisis de la construcción de la "otredad negativa" con el objetivo de fundamentar la opinión de que, contrario a lo informado en el Nunca Más ${ }^{14}$, cientos de personas han sido víctimas de persecuciones, secuestros, torturas y desapariciones durante la última dictadura cívico militar, a causa de su orientación o identidad sexual.

La construcción de una otredad negativa es una instancia crucial en un proceso genocida en tanto permite delimitar a quien habrá

\footnotetext{
13 Feierstein señala que a partir del aniquilamiento de aquellxs con capacidad de articulación política crítica, y solidaria, se estaba clausurando la posibilidad de establecer relaciones sociales de ese tipo en la Argentina "cuanto menos (al decir de algunos represores) de aquí a veinte años. Y, tristemente, cabe señalarse que dicho pronóstico fue cumplido con bastante precisión. Recién entre veinte y treinta años más tarde comienza a surgir, en las discusiones colectivas y no sólo en los pequeños grupos, la posibilidad de reconstruir una memoria que dé cuenta de este proceso de destrucción (y no meramente de una supuesta "agresión terrorista" al conjunto social)" (Feierstein, 2007:326-327).
}

14 El capítulo 2 del Informe Nunca Más, presenta como "Víctimas" (nótese el carácter desideologizado de las mismas): niñxs desaparecidxs y embarazadas, adolescentes, la familia, inválidxs y lisiadxs, religiosxs, conscriptxs, periodistas y gremialistas. Cabe preguntarse por qué lxs militantes, lxs homosexuales, las trans -fuertemente reprimidas y perseguidas - no están incluidxs en esta lista. 
que exterminar. En Argentina, el poder hegemónico, mediante operaciones rigurosamente sistematizadas y aplicadas - con complicidad cívico-militar - se nutrió de símbolos y características existentes en el imaginario colectivo, para construir desde allí nuevos símbolos, reforzando los prejuicios ya existentes, con el objetivo de construir un sujeto social como negativamente diferente. Delimitó dos campos claros: aquellxs iguales, mayoritarixs, distintxs de esxs otrxs, aquellxs que no quieren ser como todxs y, por lo tanto, no deben ser. Esto fue realizado mediante la utilización de un término político "el subversivo", y luego, lentamente se lo mixtura con un componente policial, asociándole actitudes violentas, agresivas, impulsivas, "mete bombas". Así, estx "otrx" pasó a ser objeto de accionar policial y penal convirtiéndose en el "subversivo delincuente".

Hay que aclarar que esta simplificación llevada a cabo por lxs perpetradorxs, fue de alguna manera efectiva, no sólo en su época, sino también en el pensamiento de muchxs intelectuales y de la sociedad en general en el momento post-dictatorial (ya se ha mencionado la noción de "guerra" utilizada para explicar lo sucedido). Para dar un ejemplo, en las conclusiones del Nunca Más se puede leer: "carece de validez la afirmación de que la subversión y el terrorismo fueron efectivamente vencidos. Se derrotó a algunas organizaciones terroristas, pero a cambio de implantar un sistema de terror institucionalizado, vulnerador de los más elementales principios éticos y morales inherentes a la persona humana, con respaldo doctrinario en concepciones también extrañas a nuestra identidad nacional" (CONADEP, 1984:372). Más allá de la clara mención a dos fuerzas en combate, es interesante problematizar ¿a qué se refieren al decir: "concepciones también extrañas a nuestra identidad nacional? ¿Con el "también" se incluye, aparte de la doctrina del terror, a las concepciones de "lxs subversivxs"? ¿Cuáles eran las concepciones de organizaciones como Montoneros y el ERP que se creían tan ajenas a la sociedad? Incluso en algunos momentos del Informe se plantean cuestiones como por ejemplo en el Capítulo 2.C: La familia como víctima: "Es muy difícil, en el marco de una lucha contra la subversión, encontrar una razón válida para la detención y tortura de personas de la edad de quienes 
hemos citado"; por lo tanto, podría pensarse: ¿la muerte de compañerxs militantes sí puede ser entendida fácilmente y con razones válidas? Y así se podría seguir. Estas simplificaciones se escuchan hasta el día de hoy, como un claro efecto de lo que nos dejó el genocidio de los años setenta.

Ahora bien, la intención de este trabajo es señalar que esa otredad negativa no estaba compuesta sólo por lxs "subversivxs": esta fue tan sólo "la carátula" que quisieron ponerle a un tipo de relación social, a determinados valores, encarnados en sujetxs concretxs, que debían ser eliminadxs por ser antagónicos al modelo deseado, colocándose la fuerza genocida como una suerte de ente natural, que sólo se limitaba a actuar en función de las provocaciones o resistencias planteadas por esxs otrxs "inadaptadxs y violentxs". La construcción de la negatividad, más bien, tiene vinculaciones con el potencial subvertor del sujetx o su "falta de capacidad" para adaptarse al orden.

Se intentó aniquilar a quienes "encarnaban un modo de construcción de identidad social y eliminando - material y simbólicamente- la posibilidad de pensarse de ese modo" (Feierstein, 2007:53). Por lo tanto, si uno de los principales valores que buscaron ser eliminados fue la posibilidad de construir relaciones solidarias (con el fin de implantar una economía fuertemente individualista y evitar la organización obrera-estudiantil que atentaba contra dicha manera de concebir la economía), en la figura de "subversivx delincuente" estaban incluidxs también aquellxs que no estaban encuadradxs políticamente de modo directo, sino en la lucha social: jóvenes que militaban en espacios barriales, lxs estudiantes que pedían un medio boleto, trabajadorxs sociales, docentes, aquellxs obrerxs que iban a huelga por mejores condiciones de trabajo sin ser necesariamente militantes de organizaciones de izquierda, entre tantxs otrxs.

Con la misma lógica, los homosexuales, lesbianas, trans, inter$\operatorname{sex}^{15}$, claramente pasarán a ser también parte de aquella subversión, en tanto no encajan dentro de las maneras que lxs perpetradorxs y

15 Según lo constatado, prácticamente no hay información accesible de personas intersex en estas décadas. 
la Iglesia, gran aliada en este campo, pretendían que lxs cuerpxs expresen su sexualidad y desarrollen su afectividad. Cabe aclarar, que no se trata aquí de analizar quienes eran "culpables" o "meredorxs" de ser "chupadxs" 16 , sino intentar argumentar la diversidad de sujetxs que fueron secuestradxs y desaparecidxs bajo la misma categoría (aplicada injusta y arbitrariamente a cada unx de lxs desaparecidxs).

Se puede afirmar que todos estos grupos, sumamente diversos, tenían en común, según la mirada de lxs genocidas, desafiar la "occidentalidad cristiana": noción que "en su nivel explícito es tanto política como religiosa (teniendo el elemento occidental el carácter político de alineamiento en la Guerra Fría y el elemento religioso en el carácter cristiano). Es decir, es ideológico en todo el término de la palabra, en una síntesis que resulta tanto política como religiosa" (Feierstein, 2007:64). Se puede precisar, entonces, que la práctica social genocida ocurrida en Argentina, siguió una suerte de lógica de "limpieza social" en tanto debía extraerle a la sociedad este mal enquistado en sí misma (no es casual que las salas de torturas eran llamados "quirófanos"). Para llevar a cabo dicha limpieza, se apuntó directamente sobre la persecución de las formas de autonomía política, entendida en un sentido delincuencial.

\section{¡Queremos vivir y amar libremente en un país liberado! ${ }^{17}$}

Los dictadores que "condujeron" al país durante 1976-1983 tuvieron un discurso muy preciso: la intención fue homogeneizar a la sociedad en una verticalidad ideológica, religiosa y cultural, bajo el ya enunciado lema de la "civilización occidental y cristiana. En el mismo sentido, el nombre (auto) escogido "Proceso de Reorganización Nacional” fue sumamente claro ya que expresaba la búsqueda por

\footnotetext{
16 Ser "chupadx" significaba ser secuestradx ilegalmente por las fuerzas represivas, momento a partir del cual ya nadie sabía a dónde lxs conducían.

17 Fragmento del texto escrito en los volantes que entregó el FLH el 20 de junio de 1973, a la llegada de Perón.
} 
transfigurar y reconfigurar las maneras en que se establecían las identidades dentro de la Argentina.

Resulta evidente que la sexualidad no sería un asunto descuidado por el régimen dictatorial. La heterosexualidad monogámica fue la única forma "habilitada", y en esto fueron apoyadxs fuertemente por la Iglesia. La heterosexualidad obligatoria es un concepto propuesto por Adrienne Rich (1999) en su ensayo Heterosexualidad obligatoria y existencia lesbiana, en el que hace referencia a las presiones a las que son expuestas las mujeres para cumplir con la heteronorma (como si la realización como mujer tuviese que pasar necesariamente por vincularse con un varón). Esto también puede pensarse, claramente, en relación con los mandatos impuestos sobre los varones.

Antes de realizar una aproximación a la historia de las organizaciones "diversas" durante las décadas del setenta y ochenta, es necesario explicitar que en el seno del colectivo que abarca a las diferentes expresiones de la Diversidad Sexual, siempre existió un tácito orden. Esto se plasma también en cómo y por quienes está escrita la historia y también por la cantidad de bibliografía que es factible encontrar, cuestión que ha dificultado la producción del siguiente recorrido.

\title{
La prohibición del deseo en tiempos de dictadura
}

\author{
“[...] la lucha contra la opresión que sufrimos \\ es inseparable de la lucha contra todas las demás formas \\ de opresión social, política, cultural y económica". \\ Frente de Liberación Homosexual
}

Si bien el recorte teórico estudiado trata de la década del 70 hasta la vuelta a la democracia en 1983, resulta esclarecedor mencionar algunos hechos o realidades previas. En primer lugar, durante el período de la denominada "restauración conservadora" (1930-1943), se configuró un triángulo entre la Iglesia Católica, el Ejército y el Estado, a través del cual se buscó asegurar un discurso hegemónico, basado en "Dios, patria y hogar". El mismo, denunció a lxs homo- 
sexuales como traidorxs a la patria y, a su vez, era introyectado en los sujetos, reforzando la idea que debían considerarse responsables de su "enfermedad" (el higienismo jugó aquí un rol muy importante).

Fue recién hacia principios de la década del sesenta que comenzaron a "aparecer" muchas personas que abiertamente no querían curarse de aquella "enfermedad" bajo la cual se lxs designaba. En este momento, ya no rige tanto la idea de penalización, sino más bien fuertes condiciones de discriminación de la misma sociedad hacia quienes manifestaban una identidad u orientación sexual disidente. Se puede decir que en esta década se marcó un quiebre: con la presidencia de Illia se comenzaba a desplegar un ambiente de mayor tolerancia, también en cuanto a la elección sexual. Comienzan a aparecer las fiestas y bares para gays, los cines continuados y las teteras (baños públicos).

Sin embargo, "este claro de luz, duraría muy poco. Con Onganía y la Tía Margarita (apodo inventado por la comunidad homosexual para referirse a Luis Margaride, Jefe de Policía), estos lugares comenzaron a ser objetivo de las razzias" (Maglia y Abrantes, 2010:15). Cabe aclarar que la persecución hacia las trans, por parte de las Brigadas de Moralidad, nunca se detuvo: seguían siendo perseguidas por los nefastos incisos 2 “ $\mathrm{H}$ ” y 2 " $F$ ", se las encarcelaba para averiguar antecedentes y se ejercía violencia de todo tipo contra ellas. Además, en 1965 La Federal agregó el “memorándum 40”18 a través del que podían detener a chicxs sin avisar a la Justicia.

En el año 1969, un pequeño grupo de homosexuales varones comenzaron a juntarse en las casillas del guardabarrena, en el tren de Gerli (Buenos Aires), por primera vez estaban discutiendo acerca de cómo generar un estado de conciencia sobre las condiciones en las que vivían lxs homosexuales. Allí decidieron agruparse y conformar "Nuestro Mundo", a través del cual repartían boletines mimeografiados en las redacciones de los periódicos y revistas, quienes los recibían muy sorprendidxs. Uno de los fundadores fue Hector

18 Fue derogada en 1991 después del arresto, tortura y muerte de un joven de 17 años, Walter Bulacio. Para más información se puede visitar: https://www.cidh.oas.org/annualrep/98span/Admisibilidad/ Argentina11.752.htm 
Anabitarte quien, según relata Bazan (2004) con motivo de los 50 años de la Revolución, viajó a Moscú y tuvo la oportunidad de charlar sobre sexualidad con el sexólogo de la burocracia rusa, el profesor Teodorov. Su respuesta fue eminente: "en la URSS no existe la homosexualidad", además le aconsejó que lxs que eran homosexuales deberían casarse para curarse.

Las editoriales y contenidos de "Nuestro Mundo" eran muy interesantes y estaban cargados de un fuerte contenido político y social. Una de ellas afirmaba: "la homosexualidad, no es un hecho aislado. La situación de los homosexuales está profundamente ligada a otros problemas: la diferencia discriminatoria entre los sexos, las razas, clases sociales, etcétera. Por ello, que hablar, debatir sobre la homosexualidad no puede ni debe quedar aislado de la situación, de la problemática general de la sociedad, de su desarrollo, de sus cambios, de sus perspectivas" (Bazan, 2004:338).

Entrados los años setenta, se vivía un clima de gran politización, de contestación, crítica social generalizada; en este contexto, en agosto de 1971, se conformó el Frente de Liberación Homosexual (de ahora en adelante, FLH). Surge de la fusión de "Nuestro Mundo" con un grupo de intelectuales, fundamentalmente de Ciencias Sociales (entre ellxs, Juan José Sebreli, Manuel Puig, Blas Matamoro y Juan José Hernández). Se conformó como una organización horizontal con varios grupos independientes entre sí, aún con intereses diferentes. Los grupos que se aglutinaron fueron: Nuestro Mundo (especialmente conformado por trabajadores y sindicalistas), el Grupo Profesionales (más dedicados al estudio); el grupo Bandera Negra (reunía actores y bohemios con tendencia anarquista); el grupo Safo (de mujeres) y un pequeño grupo cristiano (Emanuel). Uno de los principales líderes fue el poeta y sociólogo Néstor Perlonguer (Grupo Eros). La presencia femenina fue muy importante, aunque integrada siempre al término homosexual ya que "la palabra lesbiana apareció en 1975 con la influencia del Año Internacional de la Mujer” (Mocrovejo, 2000:196).

El FLH disputaba directamente con el sentido común y con la propuesta oficial y hegemónica. El movimiento confeccionó los Puntos Básicos de acuerdo, como un acuerdo realmente de avanzada, que 
sintetizaba los sentimientos de aquella época y asumía la identidad y orientación propia como un derecho a ser resguardado. Entre otros puntos, argumentaba que "los homosexuales son oprimidos social, cultural, moral y legalmente. Son ridiculizados y marginados, sufriendo duramente el absurdo impuesto brutalmente de la sociedad heterosexual monogámica", y sigue: "esta opresión proviene de un sistema social que considera a la reproducción como objetivo único del sexo y su expresión concreta es la existencia de un sistema heterosexual compulsivo de relaciones interhumanas donde el varón juega el papel de jefe autoritario, y la mujer y los homosexuales de ambos sexos son inferiorizados y reprimidos" (Bazan, 2004:342).

Lejos de quedarse en el papel de "meras víctimas", indican que la principal reivindicación es la derogación de la normativa antihomosexual, para lo cual debía ser desmantelado el aparato represivo ya que la opresión heterosexual era concebida como propia del capitalismo y de todo sistema autoritario. Se convoca a la alianza con movimientos de liberación nacional y social, y con los grupos feministas (Unión Feminista Argentina y Movimiento de Liberación Femenina). El FLH estuvo presente en dos momentos fundacionales del peronismo de los años setenta: la asunción de Cámpora en 1973, y en la llegada de Perón ese mismo año.

Ahora bien, al mismo tiempo que crecía la organización, la represión se recrudecía. El año 1973 puede ser visto como el momento en el que empieza a gestarse el proceso de construcción de aquella "otredad negativa" (si bien pueden verse rasgos en años y décadas anteriores, lo que concierne al proceso genocida es lo que se analiza aquí). A la persecución, encarcelamiento y ridiculizaciones constantes llevadas a cabo por las Brigadas de Moralidad, se les suma la acción sistemática y cruel ejercida por la Triple A (Asociación Anticomunista Argentina). La construcción de estx "otrx" negativo comenzó a ser incesante; en julio aparecieron pintadas algunas paredes de Buenos Aires con las inscripciones "Contra el ERP, los homosexuales y los drogadictos”. Este proceso llega a uno de sus puntos máximos en febrero de 1975, cuando en la revista El Caudillo se publicó una nota con el título "Acabar con los Homosexuales”, allí se proponía: “a los 
que ya son, proponemos que se los interne en campos de reeducación y trabajo, para que de esa manera cumplan con dos objetivos: estar lejos de la ciudad y compensarle a la Nación trabajando por la pérdida de un hombre útil. Hay que acabar con los homosexuales. Tenemos que crear brigadas callejeras que salgan a recorrer los barrios de las ciudades, que den caza a esos sujetos vestidos como mujeres, hablando como mujeres. Cortarles el pelo en la calle o raparlos y dejarlos atados a los árboles con leyendas explicativas y didácticas" (Bazan, 2004:365). Nótese que no sólo hace referencia a los homosexuales, sino también a las mujeres trans, a quienes no sólo no les reconocían su ser mujer, sino que se las ridiculizaba; incentivando, en ambos casos, a usar la violencia contra ellxs. Después de esta avanzada, quedaron unxs 30 militantes en el FLH, quienes deciden radicalizar las medidas.

Para 1975, la situación era crítica: la ofensiva genocida en tanto constituir a lxs homosexuales y trans como parte de este otro negativo era incanzable, las persecuciones incesantes y, además, el FLH y sus cercanxs tampoco eran bien vistxs por la izquierda. El ERP llegó a protestar porque a sus militantes solían encerrarlxs junto con aquellxs gays que caían presos. Por su parte, en Montoneros "ejecutaron a dos compañeros homosexuales por considerar que todos los homosexuales eran «apretables». Años más tarde [...] volví sobre el tema con Sylvina quien (lo) confirmó" (Bazan, 2004:361).

La violencia en este primer momento se expresó a través de imágenes: es la legitimación, la construcción teórica de la necesidad de un exterminio. El poder toleraba aún estas formas diferentes, pero al mismo tiempo constantemente las marcaba y las (re)construía. Esto pudo verse claramente en el hecho que, incluso hasta los primeros cuatro o cinco meses de la dictadura ya instalada, aún existían bares, fiestas y espacios "permitidos".

Este proceso de negativización y estigmatización es, por un lado, constitutivo de los modos de construcción de identidad de la mo- 
dernidad ${ }^{19} \mathrm{y}$, por otro lado, es el primer momento de una secuencia genocida, aquel que hace viable una "solución" genocida. Se trascribe un segmento de El sexo de las Locas" de Néstor Perlongher: "Hablar de homosexualidad en la Argentina no es solo hablar de goce sino también hablar de terror. Esos secuestros, torturas, robos, prisiones, escarnios, bochornos, que los sujetos tenidos por «homosexuales» padecen tradicionalmente en la Argentina —-donde agredir putos es un deporte popular- anteceden, y tal vez ayuden a explicar, el genocidio de la dictadura".

El momento de hostigamiento es propuesto por Feierstein como la segunda "etapa", concebido como el momento de transición de lo simbólico (construcción de la otredad) a lo material (a través del hostigamiento físico paraestatal). En este, las víctimas suelen tener el carácter de "articuladorxs sociales", que justamente jugaban el rol de articular a las organizaciones con otros movimientos barriales, estudiantiles, sindicales. Se puede pensar, a riesgos de tomar una visión por demás de esquemática pero asumiendo el riesgo a fin de realizar el presente ejercicio de elaboración, que a la par de lo acontecido con otros sectores del campo popular y de las organizaciones de izquierda, es también en 1975 cuando aparece Federico muerto en el Río de la Plata, un adolescente de un barrio que pertenecía al FLH y quizás (y sólo quizás) fue visto como un nexo con organizaciones barriales o como quien podía "contaminar" a aquellos sectores.

En 1975, el FLH estaba fuertemente reducido, y mientras se encontraban planeando una respuesta a un ataque papal contra la diversidad sexual, llegó la Policía y se llevó a una decena de militantes. Luego de unas reuniones más, comenzada la dictadura, el colectivo decidió disolverse. "Sólo quedaba huir o morir. O desaparecer" (Bazan, 2004:366).

El 24 de marzo de 1976 las Fuerzas Armadas tomaron el poder. Muchxs homosexuales, lesbianas y trans tuvieron que exiliarse, huyendo de tal represión. La dictadura desató una violenta y sistemática

19 Es imposible no pensar aquí en tantas frases dichas en este último año por el presidente de la Nación, Mauricio Macri, al referirse a lxs militantes, entre otras cosas para justificar, por ejemplo, los despidos masivos, como aquella "grasa militante" o el "ñoqui militante". 
persecución que, además de prácticamente imposibilitar toda forma de organización, obligó a destinar todas las fuerzas a la supervivencia individual. La Iglesia, aliada, fomentaba inculcar una visión moralizante.

Muchxs "diversxs" tenían una doble militancia: en alguna organización política partidaria y también en su propio colectivo por la reivindicación de sus derechos sexuales. Por lo tanto, muchxs fueron apresadxs por este motivo, pero muchxs otrxs fueron secuestradxs por desear y amar de una manera diferente a la que pretendía el régimen. Carlos Jáuregui (1987) en su libro La homosexualidad en Argentina, afirma que fueron 400 lxs homosexuales desaparecidxs por las fuerzas genocidas. Este dato fue proporcionado por el Rabino Marshall Meyer, quien le afirmó que, debido a las presiones constantes del ala católica de la Asamblea Permanente por los Derechos Humanos, el Informe Nunca Más no incluyó en su contenido la persecución a homosexuales. Meyer también sostuvo que habían recibido testimonios de personas que habían estado detenidas desaparecidas, informando sobre la existencia de violaciones y maltratos especialmente crueles y sádicos contra las personas que según lxs perpetradorxs eran homosexuales.

Con las vísperas del mundial, la persecución se recrudeció: según Jáuregui, unxs 1400 homosexuales y trans fueron detenidxs para "limpiar de homosexuales las calles".

Cabe aclarar que durante todo el período que implicó la dictadura cívico-militar más trágica y sangrienta de Argentina, los colectivos de gays, lesbianas y trans permanecieron sin capacidad de organización y acción. Esto muestra el fuerte golpe que significó para estxs sujetxs, que implicó echar por tierra años de lucha, en los que incipientemente se estaba consiguiendo hacer valer el derecho de, al menos, poder ser "visibles" y no tener la necesidad de esconderse para encontrarse.

Es importante recordar que el caso de las mujeres trans es particular, ya que nunca dejaron de estar severamente perseguidas: ni antes, 
ni durante, ni después. Aún hoy no son aceptadas por el conjunto de la sociedad, y cuentan cada una de ellas "más muertes que vidas", como suelen decir en los Encuentros Nacionales de Mujeres donde su voz busca ser escuchada y amplificada ${ }^{20}$. Un caso emblemático es el de Valeria del Mar Ramírez. En el año 1976 ejercía la prostitución, y debía lidiar constantemente con el maltrato policial. "Nosotras sufrimos detenciones todo el tiempo - explicaba-. No era raro que nos lleven en un patrullero a la comisaría, que nos pidan sexo". Valeria estuvo detenida dos veces, en 1976 y 1977 en el centro clandestino el Pozo de Banfield, donde fue sometida a malos tratos, torturas y violaciones. Al salir de allí tuvo que volver a "vestirse como hombre" para poder sobrevivir ${ }^{21}$, con los daños y sufrimientos que esto produjo en ella. Hoy es la primera mujer trans que recibió su nuevo documento de identidad y partida de nacimiento rectificada y es una de las pocas que aún vive para narrar lo vivido.

\title{
En las plazas, en las aulas y en las camas Honrar la memoria
}

\author{
“Arderá el amor, arderá su memoria, \\ hasta que todo sea como lo soñamos, \\ como en realidad pudo haber sido". \\ Paco Urondo ${ }^{22}$
}

A lo largo del presente trabajo, se ha argumentado que la última dictadura cívico militar constituyó una práctica social genocida, entendida como "aquella tecnología de poder, cuyo objetivo radica en la destrucción de las relaciones sociales de autonomía y cooperación y de la identidad de una sociedad, por medio del aniquilamiento de una

20 Hoy se encuentra en disputa la aprobación de la Ley de Reparación Histórica, gracias a la cual unas 300 mujeres podrían están recibiendo una pensión mensual que les garantice el derecho a la adultez/vejez que aún les aparece negada: casi ninguna de ellas cuenta con aportes jubilatorios.

21 La nota completa se encuentra disponible en https://www.pagina12.com.ar: "Ser Valeria me llevó a estar secuestrada”. Publicada el 8 de enero de 2013.

22 Extracto del poema "Dame la mano" en Son memorias (1965-1969). 
fracción relevante de dicha sociedad y del uso del terror, producto del aniquilamiento para el establecimiento de nuevas relaciones sociales y modelos identitarios" (Feierstein, 2007:83).

A modo de cierre, interesa plantear dos cuestiones en particular: por un lado, señalar ciertas potencialidades que presenta pensar la dictadura como un genocidio, y por el otro, en íntima relación, reflexionar sobre la importancia de mantener viva la memoria.

En primer lugar, entender a la dictadura como una práctica social genocida, implica poner el acento en la reconfiguración de las relaciones sociales que el proceso buscó llevar a cabo. Como ya se ha dicho, no se trató de destruir cualquier tipo de relación social, sino justamente aquellas de igualdad, autonomía y reciprocidad vigentes en la década del setenta. Se buscó, deliberadamente, implantar un nuevo modelo soberano que tenga efectos en las maneras de socialización de aquel entonces, y que conlleve efectos en las prácticas políticas de las sociedades posgenocidas. Por lo tanto, al hablar de proceso, el mismo no implica un principio y un fin terminantemente delimitados; en este sentido vuelve a ser pertinente la propuesta de Feierstein, no sólo para pensar que el genocidio argentino comenzó años antes del 24 de marzo 1976, con la construcción de la otredad negativa, sino también es iluminadora para pensar las sociedades posgenocidas, en las cuales podemos ubicar también este año 2016, año en el que siguen conviviendo en el país ex detenidxs, hijxs y nietxs que desconocen su identidad, perpetradorxs sin condena, compañerxs aún desaparecidxs. Año en el que también la memoria ha sido "bombardeada" desde el oficialismo, relativizando los hechos.

Ahora bien, el último momento propuesto es la realización simbólica de las prácticas sociales genocidas. Es un punto fundamental ya que produjeron "efectos sociales y políticos que exceden a la materialidad de la eliminación de masas de cuerpos, de individualidades, de sujetos que expresaban relaciones sociales" (Feierstein; 2007: 139). Las prácticas sociales genocidas no culminan con su realización material, sino que se realizan en el ámbito simbólico e ideológico, a la hora de representar y narrar esta experiencia, de lo contrario pierde "efectividad", ya que no se estaría asegurando la clausura de aquellos 
modos de articulación social que buscaron ser eliminados. Feierstein propone diversas modalidades de representación que pueden ser aplicadas al caso argentino.

\section{Los modos de negación de la identidad}

y transferencia de la culpa

El Informe Nunca Más produjo un discurso en el que buscó oponer a la lógica condenatoria del "por algo será", la expresión del "no hicieron nada": noción que luego fue reproducida por numerosxs intelectuales, artistas, directores de cine. Ese "no hicieron nada" es fuertemente despolitizador y desproveé a las víctimas de aquello por los cuales se los secuestró, torturó y desapareció: su autonomía política (expresada en una militancia barrial, política, sindical, o sexual en el caso de la diversidad sexual). A modo de ejemplo, se observa que se presenta a lxs desaparecidxs como personas a-históricas, asexuadas, sin aspiraciones, descontextualizados. Lxs pocxs que según esta línea son culpables, son aquellxs de las organizaciones armadas, pero, además de la infundada justificación y la injusta culpa atribuida, nada se dice sobre el surgimiento de estas organizaciones, sino que se las presenta como la locura de unxs pocxs, "olvidando" que fueron el producto de una lucha nacional y continental. De esta forma, la CONADEP inauguró una línea en la que pareciera que nunca existió en la Argentina aquello que, de alguna manera, "unificó" a lxs 30000 desaparecidxs. Así, se produjo la deseada negación de las prácticas sociales que buscaban ser clausuradas por lxs dictadorxs.

Quizás ningún ejemplo resulte tan paradigmático como es el caso del colectivo LGTBI, en su caso ni siquiera hoy son reconocidxs. No sólo se niega que "hicieron algo", sino que parecen haber sido borradxs del mapa de la historia, como si nunca hubiesen existido, olvidando así a lxs compañerxs que dieron su vida por apostar a la autonomía personal y la libertad sexual como derecho. Se trata de cientxs de personas que se animaron a ser en tiempos de dictadura, lo cual se constituye en un ejemplo de lucha y dignidad que es necesario recuperar para no volver a "olvidar". 


\section{Las lógicas de demonización y el papel del horror}

En la Argentina, bajo la teoría de los dos demonios se patologizó tanto a víctimas como a victimatarixs, ubicando a la sociedad como a la única víctima real. Conjuntamente, se muestran en los años ochenta una inmensa cantidad de recursos que exhiben los horores padecidos en los campos de concentración, pero sin ninguna explicación integral, con la intención de sumir a la sociedad en la parálisis total. Algo particular sucedió con lxs ex detenidxs que son dejadxs en libertad: por un lado, se los envió a aterrorizar, a contar lo que les había pasado, de manera que nadie más vuelva a querer hacer lo mismo. Por el otro, se envió un mensaje a la sociedad: desconfíen, por algo ellxs están vivxs. Se instaló así la desconfianza absoluta, no sólo en el ex detenidx sino también en lxs amigxs ausentes, en lxs vecinxs, en quienes no se conoce. Esto derivó en una fuerte tendencia individualista por la que la persona se refugia en sí para protegerse. De esta manera, se clausuran eficazmente las relaciones de reciprocidad y solidaridad.

En páginas anteriores se mencionó que existen evidencias que los tratos recibidos por homosexuales y trans eran especialmente crueles y sádicos, ahora bien ¿Por qué esa información permanece oculta? Aún más, personas LGTBI exiliadas por haber sido perseguidas, otras que han sobrevivido al cautiverio, mujeres trans que debieron esconderse haciéndose pasar por hombres para sobrevivir. ¿Dónde están estos testimonios? Lejos de pensar en una responsabilidad individual de estxs compañerxs, debemos preguntarnos, ¿qué lugar de escucha se garantiza socialmente? Valeria del Mar Rodriguez fue la única que dio testimonio de que tanto ella como sus compañeras eran detenidas por ser trans. Este trabajo busca ser una apuesta por el reconocimiento a la lucha de tantxs, y no necesariamente una lucha partidista, sino antes que nada una lucha por ser, por amar y desear libremente. Quizás sea esta la primera de las batallas. Por esto, recuperar sus historias, sus nombres, sus sueños, es fundamental para honrar su lucha y hacerla de todxs.

Para cerrar estas reflexiones finales, y con la intención de velar por mantener la memoria viva, se ha dicho que la memoria ha sido 
bombardeada, en particular por el presidente electo durante el 2015, Mauricio Macri. ¿A qué se hace referencia con esto? Debajo de un manto ilusorio de respeto por los derechos humanos, él mismo se refirió a la dictadura de 1976 como una "guerra sucia”, nada más y nada menos que en la misma entrevista en la que afirma desconocer si fueron 9000 o 30000 lxs desaparecidxs, advirtiendo que esto no es un dato importante. No hay lugar para expresiones de este tipo, ya que se está haciendo referencia a la etapa más trágica de la historia reciente y, especialmente porque implica compañerxs, implica madres, abuelas, nietxs. No deben escatimarse jamás los cuidados por nombrar las cosas por lo que realmente son: un genocidio contemporáneo.

En la misma lógica, el número de desaparecidxs no es menor: son historias, amores, pasiones, sueños, luchas y, al mismo tiempo, llegar a este número fue un largo y doloroso proceso de los organismos de Derechos Humanos, por lo cual pretender bombardear y plantear dudas sobre su veracidad, es querer plantear dudas sobre estos mismos organismos. Y, como sociedad, no podemos dejar que esto ocurra: les debemos la valentía, el coraje, la fuerza. Fueron estos quienes se pusieron en pie y, en el caso de las Madres, quienes empezaron a caminar cuando todxs seguían encerrados por terror, porque gracias a ellas los pañuelos blancos nunca más serán trozos de tela.

\section{Referencias bibliográficas}

BAZAN, O. Historia de la homosexualidad en la Argentina. De la Conquista de América al siglo XXI. Buenos Aires, Marea, 2004.

BUTLER, J. Cuerpos que importan. Sobre los límites materiales y discursivos del "sexo". Barcelona, Paidós, 2007.

CARBAJAL, M. Entrevista a Bazan. La Plata. Universidad Nacional de La Plata, Facultad de Humanidades y Ciencias de la Educación, Departamento de Sociología, 2004. [En línea: 15/07/2017] Disponible en: http://www.fahce.unlp.edu.ar/academica/ areas/sociologia.

COMISIÓN NACIONAL SOBRE LA DESAPARICIÓN DE PERSONAS (CONADEP) Nunca Más. Buenos Aires, Eudeba, 1984. 
DORLING, E. Sexo, género y sexualidades: introducción a la teoría feminista. Paris, PUF, 2008.

DRAMIS, A. "Rápido y furioso”, en: Diario Página 12, Buenos Aires, 22 de abril de 2016. [En línea: 09/12/2016]. Disponible en: https://www.pagina12.com.ar/diario/ suplementos/soy/1-4500-2003-09-21.htm

DUHALDE, L. A. El Estado terrorista Argentino. Quince años despúes, una mirada crítica. Buenos Aires, Eudeba, 1999.

ELIZALDE, A.; MORBELLI, M.C., PERALTA, M. Trabajo final de la Asignatura Práctica Profesional II. Universidad Nacional de Rosario, Escuela de Trabajo Social. Rosario, 2014.

FABBRI, L. Apuntes sobre feminismos y construcción de poder popular. Rosario, Puño y Letra, 2013.

FEIERSTEIN, D. El genocidio como práctica social: entre el nazismo y la experiencia argentina. 2da. Ed. 1ra.reimp. Ciudad Autónoma de Buenos Aires, Fondo de Cultura Económica, 2014.

HILLER, R. El activismo de la diversidad sexual en la Argentina. 2013. [En línea: 09/12/2016]. Disponible en: http://biblio.sigla.org.ar/index.php?option=com_k2\&view=i tem\&id=155:homosexualidad-en-tiempos-de-dinosaurios \&lang=es

CAUSAS JUDICIALES CONTRA LOS GENOCIDAS DE ARGENTINA. Hubo más de 400 homosexuales desaparecidos durante la dictadura. 26 de enero de 2011. [En línea: 12/12/2016]. Disponible en: http://casapueblos.blogspot.com.ar/2011/01/hubo-mas-de400-homosexuales.html

LA FOGATA. "Luchas con perspectiva de género”. s/f. [En línea: 09/12/2016] Disponible en: http://www.lafogata.org/06arg/arg3/arg_25-3.htm

SALGUERO, C. El plan Cóndor. Origen, desarrollo y consecuencias. 2011. [En línea: 09/12/2016]. Disponible en: http://www.papelesdesociedad.info/IMG/pdf/el-plan-condor. pdf

JAUREGUI, C. L. La homosexualidad en la Argentina. Buenos Aires, Tarso SA, 1987.

MAGLIA, E. y ABRANTES, L. "Genealogía de la Homosexualidad en la Argentina". VI Jornadas de Sociología de la Universidad Nacional de La Plata, Facultad de Humanidades y Ciencias de la Educación. La Plata, 2004.

MIRA, A. Para entendernos. Barcelona, La Tempestad, 2002.

MOCROVEJO, N. Un amor que se atrevió a decir su nombre. La lucha de las lesbianas y su relación con los movimientos homosexual y feminista en América Latina. México D.F, Plaza y Valdez, 2010.

MORENO, A. Introducción elemental a Pierre Bourdieu. Bogotá, Editer, 2003. 
PERLONGHUER, N. Cadáveres. 1987. [En línea: 12/12/2016] Disponible en: el-placard. blogspot.com.ar/poemas-de-nestor-perlongher.html?=1

RICH, A. "La heterosexualidad obligatoria y la existencia lesbiana”, en: NAVARRO, M.; STIMPSON, C.R. (comps.). ¿Qué son los Estudios de Mujeres? Buenos Aires, Fondo de Cultura Económica, 1999. Pp. 159-211.

RODRIGUEZ, R. Género, deseo y derechos humanos en Argentina. 2009 [En línea: 10/12/2016]. Disponible en: https://www.topia.com.ar/articulos/ genero-deseo-y-derechos-humanos-argentina

ROMERO, L. A. Breve historia contemporánea de la Argentina. Buenos Aires, Fondo de Cultura Económica, 1994. 